06

\title{
Способ получения тонких пленок графита и оксида алюминия
}

\author{
(C) К.М. Маханов, ${ }^{1}$ К.Т. Ермаганбетов, ${ }^{1}$ Л.В. Чиркова, ${ }^{1}$ М.А. Маукебаева ${ }^{2}$ \\ ${ }^{1}$ Карагандинский государственный университет им. акад. Е.А. Букетова, \\ 100028 Караганда, Республика Казахстан \\ ${ }^{2}$ Жетысуский государственный университет им. И. Жансугурова, \\ 040009 Талдыкорган, Республика Казахстан \\ e-mail: makanov@inbox.ru
}

(Поступило в Редакцию 29 ноября 2016 г.)

\begin{abstract}
Предложен простой и доступный метод приготовления пленок графита и оксида алюминия. Исследованы оптические свойства раствора с частицами графита и раствора глины с высоким содержанием оксида алюминия. Установлено, что в различных слоях растворов оптическая плотность различна. Наименьшая оптическая плотность соответствует верхним слоям раствора. Путем забора части раствора с разных глубин кювет подготовлены пленки графита и оксида алюминия. Исследована микроструктура пленок. Обнаружено, что частицы оксида алюминия формируют правильные формы в виде „снежинок“. Показано, что пленки оксида алюминия, изготовленные из проб, взятых на разных глубинах раствора, имеют различные толщины. Размеры частиц в более тонких пленках составляют порядка $0.29 \mu \mathrm{m}$, для самых толстых пленок от $2.81 \mu \mathrm{m}$ и более.
\end{abstract}

DOI: $10.21883 /$ JTF.2017.07.44678.2113

\section{Введение}

Благодаря своим уникальным свойствам углеродные пленки находят широкое применение в технике и промышленности [1-4]. Известны случаи их применения в качестве покрытий для лазерных дисков [5], просветляющих покрытий [6].

Существуют различные методы получения углеродных пленок: магнетронное распыление графита [7-9], распыление графита ионным пучком [10,11], лазерная абляция мишени [12]. Все они требуют создания специальных условий с применением сложного и дорогостоящего оборудования [13].

Целью работы является разработка метода получения пленок графита и оксида алюминия и исследование их оптических и морфологических характеристик.

В работах $[14,15]$ отмечено, что, если измельчить вещество механическим путем до мельчайших размеров, то в общей массе полученных частиц некоторая их доля может иметь размеры порядка сотен и менее нанометров.

Естественно предположить, что при растворении полученного порошка скорость оседания частиц и соответственно их распределение по толщине раствора будут зависеть от массы и размеров. В первую очередь на дно опустятся самые тяжелые частицы, частицы средних размеров (и массы) будут опускаться на дно сосуда с меньшей скоростью, а самые легкие окажутся в верхних слоях растворителя и могут оставаться во взвешенном состоянии более длительное время.

Основная идея предлагаемого метода заключается в том, что, используя пробы, взятые с разных глубин раствора, можно приготовить пленки с различными толщинами, поскольку толщина пленок должна определяться геометрическими размерами частиц.

\section{Методика эксперимента}

В качестве материалов для исследований использовались монокристаллический графит и природная глина с высоким содержанием оксида алюминия. Частицы графитового материала и оксида алюминия были подготовлены путем механического измельчения порошкообразного материала в ступке. В качестве растворителя для графита использовали толуол. Глину растворяли в дистиллированной воде.

Для приготовления пленок с помощью пипеток производился отбор раствора с глубин 1, 2.5 и $3.5 \mathrm{~cm}$. Отобранные пробы наносились на предварительно очищенную и обезжиренную поверхность кварцевых подложек. При подготовке пленок для микроструктурных измерений с использованием электронного микроскопа пробы наносились на стеклянные подложки с проводящим слоем на основе оксида олова, допированного фтором. Перед использованием пипетки и подложки

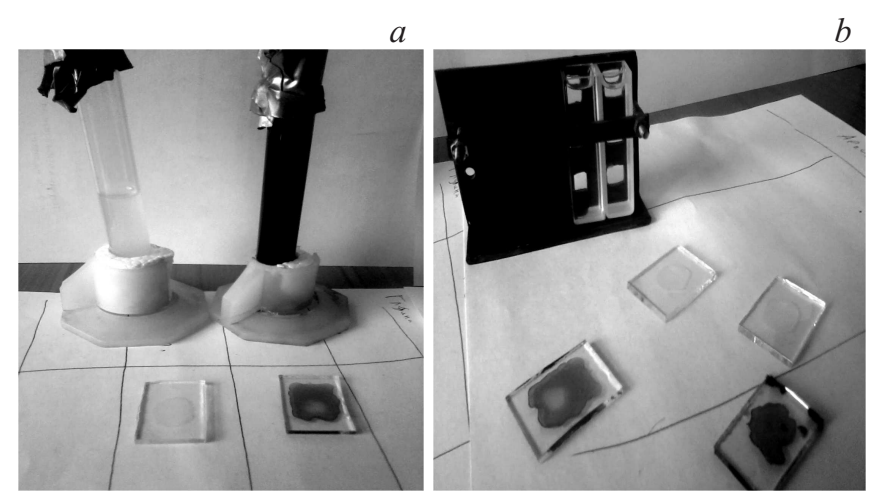

Рис. 1. Емкости с подготовленными растворами $(a)$, кюветный держатель $(b)$ и образцы пленок. 
тщательно очищались. Для исключения попадания на поверхность пленок „инородных“ тел подложки хранились в герметически закрытых стеклянных емкостях.

Для измерения спектров поглощения исходных растворов и пленок в диапазоне 350-900 nm использовался спектрофотометр СФ-46. Исследование микроструктуры пленок осуществлялось с помощью электронного микроскопа MIRA3 LMU (TESCAN, Чехия).

Для измерения спектров поглощения на различных глубинах растворов был изготовлен кюветный держатель с узкими окнами на высоте $1,2.5$ и $3.5 \mathrm{~cm}$ от верхнего края кюветы (рис. 1). Окна на передней стенке держателя ограничивали диаметр светового пучка, а также служили ориентиром для точного определения измеряемой глубины раствора. Регулировка кювет по высоте осуществлялась с помощью специально собранного подъемного устройства на базе шагового двигателя с шестереночным приводом. Привод обеспечивал плавность подъема и спуска держателя кювет на необходимую высоту.

Подготовленные растворы предварительно выдерживались в течение $6 \mathrm{~h}$ в кюветном отделении. Предполагалось, что за этот промежуток времени на поверхности останутся самые легкие частицы.

\section{Результаты и обсуждение}

На рис. 2 представлены спектры поглощения растворов.

Из полученных зависимостей видно, что оптическая плотность $(D)$ раствора глины на глубине $1 \mathrm{~cm}$ от поверхности составляет около 0.04 (кривая 1). При этом измерения на глубине $2.5 \mathrm{~cm}$ от поверхности показали (кривая 2) небольшое увеличение величины поглощаемой энергии $(D=0.2)$. С ростом глубины до $3.5 \mathrm{~cm}$, оптическая плотность резко увеличивается и составляет 0.2 на длине волны $740 \mathrm{~nm}$ (кривая 3).

Максимальное значение оптической плотности $D=$ $=0.6$ соответствует длине волны $380 \mathrm{~nm}$. При этом

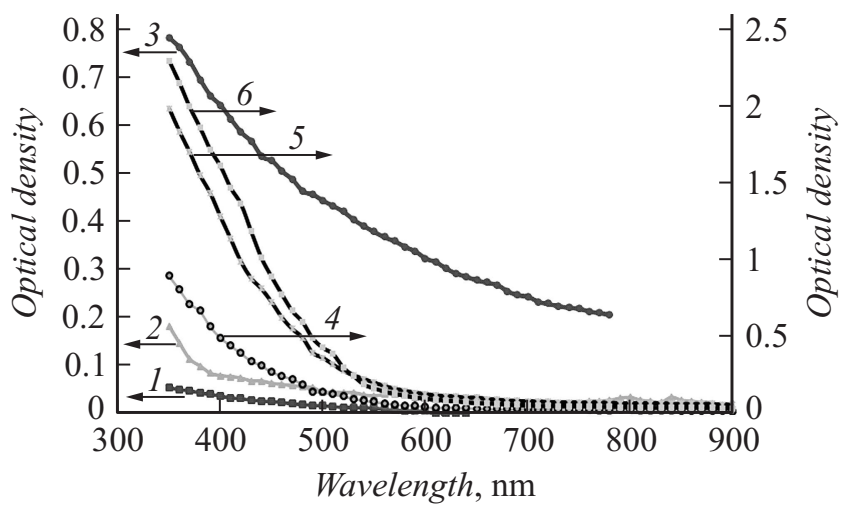

Рис. 2. Спектры поглощения водных растворов глины с высоким содержанием оксида алюминия (кривые 1-3) и частиц графита в толуоле (кривые 4-6).

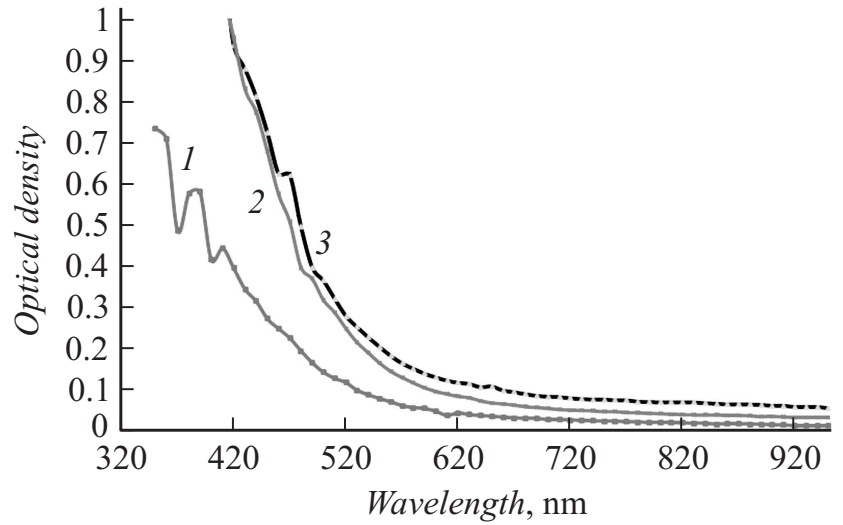

Рис. 3. Спектры поглощения пленок графита. Отбор проб для изготовления пленок осуществлен с трех различных глубин емкости с раствором: $1 \mathrm{~cm}$ (кривая 1), $2.5 \mathrm{~cm}$ (кривая 2), $3.5 \mathrm{~cm}$ (кривая 3).

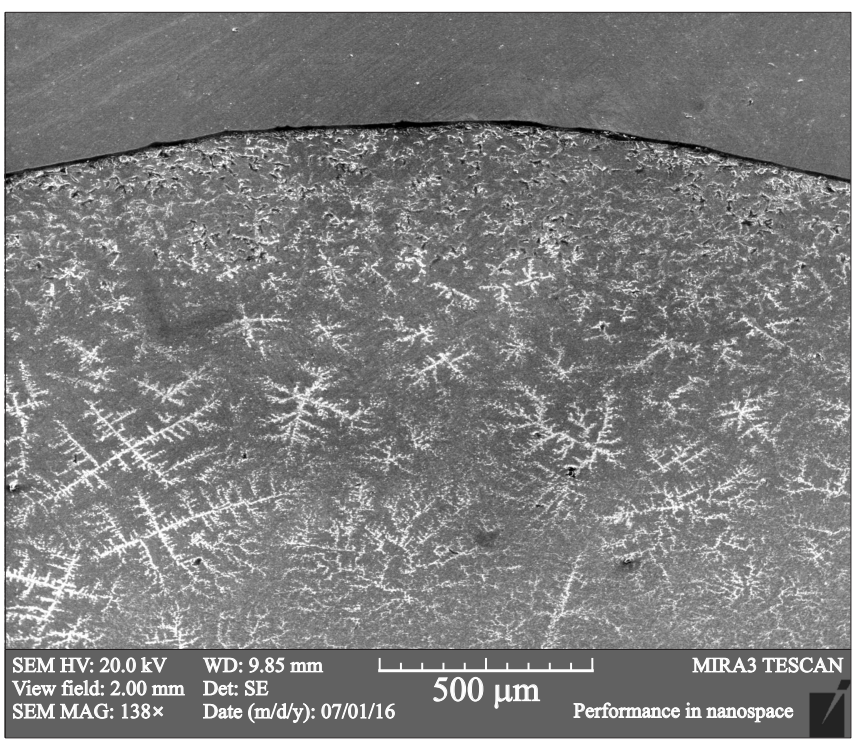

Pис. 4. Фотография микроструктуры пленки оксида алюминия. Для наглядности представлена область раздела границ.

следует отметить, что спектры поглощения раствора глины, измеренные в диапазоне 350-900 nm, не имеют выраженных колебательных полос поглощения.

Аналогичные результаты были получены для раствора с частицами графита. Установлено, что оптическая плотность на глубине $1 \mathrm{~cm}$ соответствует величине $D=0.29$ (кривая 4 на рис. 2) в коротковолновой части спектра и снижается до нуля в ее длинноволновой части. Как следует из рисунка, выраженные полосы поглощения в растворе с частицами графита также отсутствуют.

Анализ полученных зависимостей показал, что оптическая плотность растворов растет с увеличением глубины отбора проб. Полученные результаты можно объяснить либо малым количеством, либо отсутствием поглощающих центров. Это можно рассматривать также 

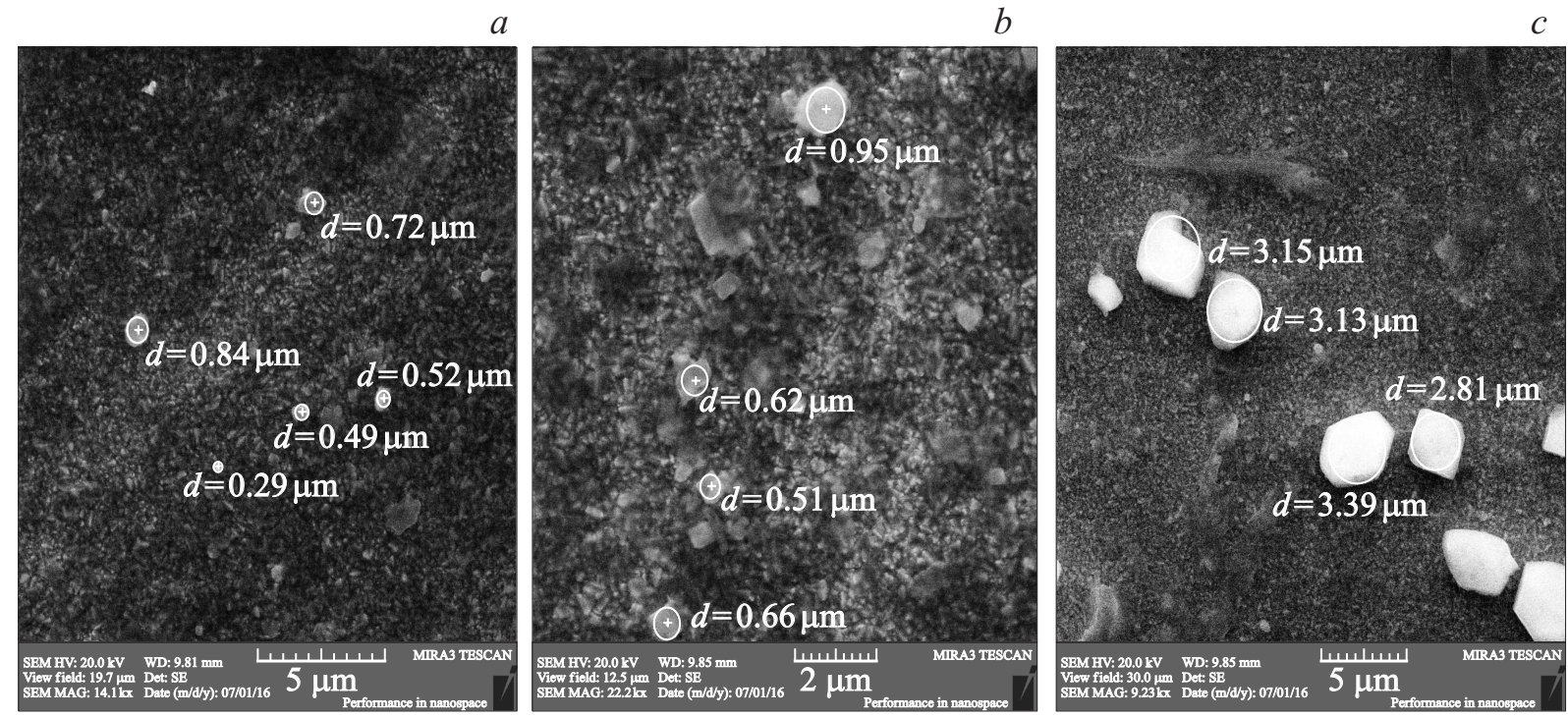

Рис. 5. Фотографии частиц оксида алюминия в пленках: $a-$ изготовленной из пробы, взятой на глубине $1 \mathrm{~cm}, b-$ на глубине $2.5 \mathrm{~cm}, c$ - на глубине $3.5 \mathrm{~cm}$.

как косвенное доказательство правильности идеи, положенной в основу предлагаемого метода.

Следующий этап эксперимента был посвящен исследованию оптических свойств пленок, полученных из данных растворов.

Были измерены спектры поглощения пленок, содержащих частицы графита и оксида алюминия. Установлено, что в целом зависимость, полученная для пленок, изготовленных из раствора глины, аналогична зависимости, полученной для ее раствора.

На рис. 3 представлены спектры поглощения пленок графита, полученных из проб, отобранных на трех указанных выше глубинах раствора.

Как следует из представленных данных, оптическая плотность пленки, полученной из пробы, взятой с глубины в $1 \mathrm{~cm}$ под поверхностью раствора (кривая 1 ), значительно меньше, чем оптические плотности пленок, полученных из проб, взятых на больших глубинах. Кроме того, в спектрах наблюдаются полосы, характерные для колебательных переходов. Природа данных полос пока не выяснена. Можно предположить, что они могут быть связаны с присутствием в растворе глины различных примесей. В целом общий ход кривых поглощения свидетельствует о наличии центров поглощения в коротковолновой области.

Таким образом, исследование спектров поглощения пленок показало, что пленки, полученные из проб, отобранных на разных глубинах растворов, отличаются величиной плотности поглощения. При этом наименьшее поглощение наблюдается для пленок, полученных из проб, взятых на глубине $1 \mathrm{~cm}$.

Более подробная информация о размерах частиц графита и оксида алюминия и структуре пленок была получена при исследовании микроструктуры пленок с помощью электронного микроскопа.

Фотография микроструктуры пленок с частицами оксида алюминия представлена на рис. 4. Фотография сделана на разделе границы „пленка-подложка“. Из снимка видно, что частицы оксида алюминия образуют формы, близкие к форме снежинок, т.е. наблюдается не хаотичный разброс, а упорядоченное расположение частиц.

На рис. 5 представлены фотографии частиц оксида алюминия из трех разных пленок. Фотографии частиц на рис. 5, $a$ соответствуют пленке, полученной из пробы, взятой на глубине $1 \mathrm{~cm}$. На рис. 5, $b, c$, представлены фотографии частиц пленок, полученных из проб с глубин 2.5 и $3.5 \mathrm{~cm}$ соответственно.

Из данных фотоснимков видно, что размеры частиц по мере увеличения глубины забора проб увеличиваются. Минимальный размер для глубины $1 \mathrm{~cm}$ соответствует $0.29 \mu \mathrm{m}$ (рис. 5, a), максимальный для глубины $3.5 \mathrm{~cm}$ достигает $3.39 \mu \mathrm{m}$ (рис. 5,c).

\section{Заключение}

Таким образом, на данном этапе работ нами показана возможность получения пленок графита и оксида алюминия простым безвакуумным способом. Путем отбора проб с различных глубин раствора удалось получить пленки различной толщины на кварцевых подложках. Минимальный размер частиц оксида алюминия, содержащихся в пробах, отобранных из верхних слоев растворов (глубиной $1 \mathrm{~cm}$ от поверхности), составляет $0.29 \mu \mathrm{m}$, при увеличении глубины забора размер частиц возрастает до 2.81 и более $\mu \mathrm{m}$. 
Исследование морфологии поверхности пленок оксида алюминия показало, что частицы образуют формы, близкие к форме снежинок.

\section{Список литературы}

[1] Хомченко В.С., Сопинский Н.В., Савин А.К., Литвин О.С., Заяч, Н.С., Хачатрян В.Б., Корчевой А.А. // ЖТФ. 2008. Т. 78. Вып. 6. С. 84-89.

[2] Коншина E.A. Аморфный гидрогенизированный углерод и применение его в оптических устройствах. СПб.: СПб НИУ ИТМО, 2010. $91 \mathrm{c}$.

[3] Новиков Л.С., Воронина Е.Н. Перспективы применения наноматериалов в космической технике. М.: Университетская книга, 2008. 188 с.

[4] Щербаков А.А., Лесничий Я.В. // Труды МФТИ. 2012. Т. 4. № 3. C. 109-113.

[5] Ястребов С.Г., Иванов-Омский В.И., Рихтер А. // ФТП. 2003. Т. 37. Вып.10. С. 1193-1196.

[6] Гадомский О.Н., Алтунин К.К., Ушаков Н.М., Кособудский И.Д., Подвигалкин В.Я., Кульбацкий Д.М. // ЖТФ. 2010. Т. 80. Вып. 7. С. 83-89.

[7] Оскомов К.В., Соловьев А.А., Работкин С.В. // ЖТФ. 2014. Т. 84. Вып. 12. С. 73-76.

[8] Костановский А.В., Жиляков Л.А., Пронкин А.А., Кириллин A.B. // Nanosystems, Nanomaterials, Nanotechnologies. 2008. Vol. 6. N 3. P. 911-917.

[9] Звонарева Т.К., Лебедев В.М., Полянская Т.А. и др. // ФТП. 2000. Т. 34. Вып. 9. С. 1135-1141.

[10] Борисов А.М., Машкова Е.С., Экшайн В. // Вопросы атомной науки и техники. 2002. В. 1-2. С. 122-125.

[11] Семенов А.П., Белянин А.Ф., Семенова И.А. и др. // ЖТФ. 2004. Вып. 5. С. 101-104.

[12] Шатохин А.Н., Путилин Ф.Н., Румянщева М.Н., Гаськов А.М. // Вестник МГУ. Сер. 2. Химия. 2007. Т. 48. № 4. C. $271-276$.

[13] Суздалев И.П. Нанотехнология: физико-химия нанокластеров, наноструктур и наноматериалов. М.: КомКнига, 2006. 592 c.

[14] Ковтун Г.П., Веревкин А.А. Наноматериалы: технологии и материаловедение. Обзор. Харьков: ННЦ ХФТИ, 2010. $73 \mathrm{c}$.

[15] Русанов А.И. Термодинамические основы механохимии. СПб.: Наука, 2006. 221 с. 